doi: $10.15407 /$ ujpe60.08.0826

\title{
VIKTOR GRYGOROVYCH BAR'YAKHTAR (to the 85-th anniversary of his birthday)
}

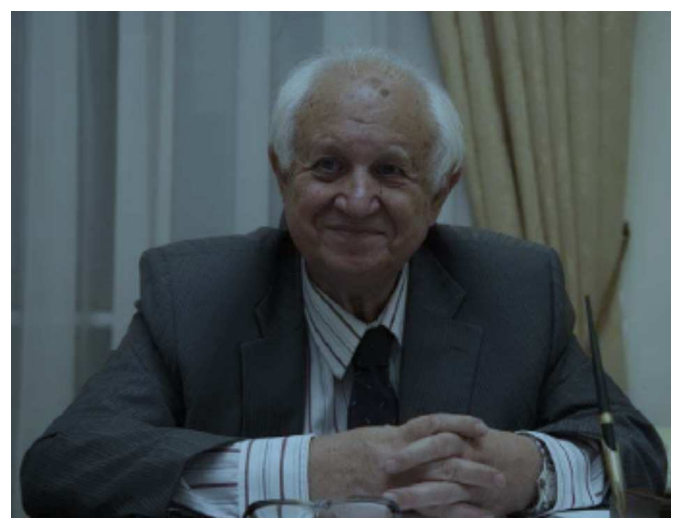

On August 9, 2015, Viktor Grygorovych Bar'yakhtar, an outstanding Ukrainian scientist known for his excellent results obtained in theoretical physics, physics of magnetic phenomena, solid state physics, environmental problems associated with the Chornobyl accident, as well as nuclear power engineering and nuclear disarmament, is 85 years of age. He is a talented organizer in science. He is the author and a coauthor of more than 300 scientific works, including 30 monographs and five textbooks on physics (two of them are intended for higher educational institutions, and three for secondary schools). V.G. Bar'yakhtar's works are widely cited (3211 citations without selfcitations). On the average, every of his scientific work was cited 11 times. His h-index equals 28.

Viktor Grygorovych Bar'yakhtar started his scientific activity in 1954 in Kharkiv under the supervision of the outstanding representative of the Kharkiv school of theoretical physics Academician O.I. Akhiezer, who had already been known to the world scientific community at that time. The early works of Viktor Grygorovych were devoted to the calculation of the emission processes of $\gamma$-quanta, which arise at the collision of electrons with a nucleus, and to the problem of vacuum polarization. These works were carried out at the Kharkiv PhysicoTechnical Institute and solved one of the most important problems in quantum electrodynamics at that time. Later on, there was the arduous toil over many problems in theoretical physics. Let us consider the main scientific problems that V.G. Bar'yakhtar dealt with.

In 1955, O.I. Akhiezer headed a scientific group with V.G. Bar'yakhtar and S.V. Peletminskii as its members. The group was aimed at solving three scientific problems: the construction of the phenomenological theory of ferromagnetism, the development of the theory of relaxation phenomena in ferromagnets, and the research of the interaction between sound vibrations and sound waves. While solving the first problem, a formula for the energy and momentum fluxes in ferromagnets was obtained for the first time, and a condition required for the determination of a magnetization value in the ground state was formulated. In addition, a new relaxation term was inserted into the Landau-Lifshitz equation, which gave rise in a natural way to a modification of the absolute value of magnetization vector. As to the second problem, the relaxation processes in the magnetic and lattice subsystems were studied, as well as the processes of interaction between them. It was demonstrated that the slowest relaxation process is the process associated with the exchange between phonons and spin waves. While researching the third problem, a possibility of the transformation of sound waves into spin ones and vice versa was established, which became a basis for the creation of delay lines for radio signals.

The next task for this scientific team was the research of processes in plasma in the presence of 
an external magnetic field. V.F. Aleksin, an expert in plasma physics, was invited into the group. A new mechanism of relaxation in plasma was revealed, and conditions for this mechanism to dominate were determined. While researching the quantum electric and heat fluxes in metals, the conditions were found under which the symmetry of the coefficients of electric and heat conductivities can be restored. This work had attracted a large scientific interest, because the electric and heat flux operators were introduced there for the first time. It should be noted that the team of researchers - O.I. Akhiezer, V.G. Bar'yakhtar, and S.V. Peletminskii - had been successfully working for more than 16 years. For a cycle of works on the magnetoacoustic resonance (interaction between spin and acoustic waves), the group was awarded the State Prize of the Ukrainian SSR.

In the 1970s, M.V. Chetkin and collaborators observed a drastic growth of the decelerating coefficient for domain walls moving at the sound velocity. At the same time, if the velocity of domain walls exceeded the sound velocity, the decelerating coefficient restored its previous value. This phenomenon was explained by V.G. Bar'yakhtar and B.O. Ivanov. They showed that the role of the mechanism governing the features of the deceleration coefficient is played by a specific coherent sound emission by a domain wall with finite thickness, provided that the velocities of the domain wall and sound coincide.

In the early 1970 s, by the invitation of the Academician O.O. Galkin, the Director of the Donetsk Institute for Physics and Engineering, V.G. Bar'yakhtar and his disciples moved to Donetsk in order to develop the researches in theoretical physics and the theory of magnetic phenomena. The researches in physics of cylindrical magnetic domains (CMDs) gained an impetus at that time. The interest in those domains consisted in that they could form a basis for the creation (for the first time) of devices, which could register and transfer information without moving the film mechanically. Still remaining in Kharkiv, V.G. Bar'yakhtar together with his disciples V.V. Gann and Yu.I. Gorobets published two works on the properties of these specific magnetic domains, which exist in materials with high magnetic anisotropy. In the city of Donetsk, V.G. Bar'yakhtar together with Yu.I. Gorobets actively continued these researches. They discovered a phase transition in a hexagonal lattice, when the lattice parameters change, but the lattice symmetry does not. Later on, Yu.I. Gorobets together with his disciples managed to observe this phase transition experimentally. The manufacture of high-quality films was one of the problems on the way to the practical application of CMDs. The fabrication procedure demanded that a lot of employees (mainly women) should be involved in checking the film quality. V.G. Bar'yakhtar and Yu.I. Gorobets proposed to monitor it with the use of resonance properties. After a series of laboratory tests, this method was introduced in the industry, which allowed many employees to be released and, simultaneously, the labor productivity and the product control quality to raise considerably.

The problem of solving the nonlinear equations has been and remains one of the key problems in theoretical physics. Before the mid-1970s, the basic properties of nonlinear formations, which were called solitons, had been elucidated. The properties of those quasiparticles make them considerably different from ordinary particles and other quasiparticles. Namely, at the collision of solitons, their velocities do not vary, whereas the coordinates change in a jump-like manner; for ordinary particles, on the contrary, their momenta change considerably, whereas their coordinates almost do not. For the first time in the world literature, V.G. Bar'yakhtar, I.V. Bar'yakhtar, and L. Economou reconstructed the collision integral and found the entropy flux. This work put end to ideological difficulties in the soliton kinetics.

\section{Teaching Activity}

At L.D. Landau's scientific school, the following rule was strictly obeyed: every research worker of the department had to lecture. O.I. Akhiezer also adhered to this rule. Therefore, in 1959, he charged V.G. Bar'yakhtar to lecture a course on the physical kinetics at the Kharkiv University. Since then and till 2012, Viktor Grygorovych excellently gave lectures at the Kharkiv (1959-1972), Donetsk (1972-1982), and Kyiv (1983-1995) Universities and at the National Technical University of Ukraine "Kyiv Polytechnic Institute" (1995-2012).

From 1974, V.G. Bar'yakhtar lectured a course of general physics at the Donetsk University, which be-

ISSN 2071-0194. Ukr. J. Phys. 2015. Vol. 60, No. 8 
came its favorite course of lectures. Nowadays, Viktor Grygorovych is the Honored Doctor of all those universities.

\section{Scientific-Managerial Activity}

In 1979, V.G. Bar'yakhtar was appointed the head of the Donetsk scientific center. It was a period when his managerial talent revealed itself. A widely recognized achievement of Viktor Grygorovych as the head of the Donetsk scientific center was a combination of the scientific activity of a variety of research organizations belonging to the coal and metallurgy industry, on the one hand, and the institutes of the Academy of Sciences of the UkrSSR, on the other hand, as well as their close interaction with the Donetsk and Lugansk regional governments, which made it possible to implement scientific developments in the industry. Later on, V.G. Bar'yakhtar continued to pay a special attention to the scientific-managerial activity. In 1982, he was elected the Academician-Secretary of the Division of Physics and Astronomy of the Academy of Sciences of the UkrSSR and, in 1991, the VicePresident of the National Academy of Sciences of Ukraine.

Being on the position of Academician-Secretary, Viktor Grygorovych organized a close cooperation with the Division of Physics and Astronomy of the Academy of Sciences of the USSR. On his initiative, the scientific achievements of all institutes composing the Division of Physics and Astronomy of the AS of the UkrSSR were discussed at the sessions of the Division. On the position of Vice-President of the NAS of Ukraine, V.G. Bar'yakhtar gave the main attention to the problems associated with the elimination of consequences of the accident at the Chornobyl nuclear power plant (ChNPP) and to the creation of a number of organizations, institutes, and faculties dealing with various scientific areas: the Institute of Radio Astronomy of the NASU in Kharkiv, the Institute of Applied Physics of the NASU in Sumy, the Institute of Electronic Physics in Uzhgorod, the Faculty of Physics and Mathematics at the Kyiv Polytechnic Institute, and the Chair of Mathematical Physics at the Taras Shevchenko National University of Kyiv. From 1985 till 1989, V.G. Bar'yakhtar was the Director of the Institute of Metal Physics of the AS of Ukraine. From 1995 till 2015, he headed the Institute of Magnetism of the
NASU and the Ministry of Education and Science of Ukraine.

\section{Chornobyl Atomic Power Station, Atomic Power Engineering, and Disarmament}

Since the first days of the Chornobyl disaster, V.G. Bar'yakhtar actively participated in the elimination of consequences of this technogenic accident, paying a lot of time and forces to this problem up to 1998. The scientific and scientific-managerial work aimed at the elimination of consequences of ChNPP was described in three collective monographs in detail, where V.G. Bar'yakhtar was the Editor-in-Chief (G.I. Palshin was the deputy Editor-in-Chief), which were published in Ukrainian, Russian, and English (the latter edition is widely known in the USA and the Western Europe). V.G. Bar'yakhtar also made a report at the United Nations Organization devoted to the elimination of consequences of the Chornobyl accident. In addition, many reports were made by him at various international conferences devoted to this issue.

For a long time, Viktor Grygorovych had been an Adviser to the Presidents of Ukraine L.M. Kravchuk and L.D. Kuchma on the matter of atomic power engineering and nuclear weapon. He actively participated in the negotiations devoted to the renunciation from nuclear and strategic offensive weapons by Ukraine. Note that it was the results of calculations made by V.G. Bar'yakhtar that allowed the negotiations, which became bogged down owing to the impossibility to estimate the amount and the cost of weapons-grade uranium, to be renewed.

The versatile, active, and fruitful activity of V.G. Bar'yakhtar won well-deserved recognition. In 1978, he was elected Academician of the AS of the UkrSSR for scientific merits. He is a winner of the M.M. Bogolyubov International Prize awarded by the Joint Institute for Nuclear Research (Dubna, Russia), the L.D. Landau Prize of the Italian Physical Society, and the Prize of the International Associations of Scientists and Catholic Foundation of St. Valentine (Italy). Pope John Paul II awarded him a memorable medal for his activity in overcoming the consequences of the Chornobyl accident. He was awarded three times with the State Prize of Ukraine: in 1972 and 1986 in the branch of science and engineering, and 
in 1999, in the branch of ecology. V.G. Bar'yakhtar is an Honored Worker of Science and Engineering of Ukraine and the winner of the K.D. Sinelnikov, N.M. Krylov, M.M. Bogolyubov, and S.I. Pekar Prizes awarded by the NAS of Ukraine. He is the Hero of Ukraine. He is also awadred the Order of the Labor Red Banner, the Order of Lenin, the Order of Prince Yaroslav the Wise (5th class), the V.I. Vernadskyi Gold Medal of the NAS of Ukraine, the K.D. Ushynskyi Gold Medal of the National Academy of Pedagogical Sciences of Ukraine. In addition, he is a full holder of the Order of Merit.

V.G. Bar'yakhtar is one of the founders and the first President of the Ukrainian physical society. For many years, he was the head of the permanent commission of the Presidium of the NAS of Ukraine on the Chornobyl disaster, an Adviser to the President of Ukraine on the matter of atomic power engineering and nuclear weapon. In 2003, Viktor Grygorovych
Bar'yakhtar was elected Honored Member of the European Physical Society and Honored Academician of the National Academy of Pedagogical Sciences of Ukraine. It is also elected Honored Doctor at the Taras Shevchenko National University of Kyiv, the National Technical University of Ukraine "Kyiv Polytechnic Institute", the V.N. Karazin National University of Kharkiv, the M.P. Dragomanov National Pedagogical University, the V.I. Dal' East Ukrainian National University, the Vasyl Stefanyk Precarpathian National University, the I.I. Mechnikov National University of Odesa, the M.M. Bogolyubov Institute for Theoretical Physics, and the G.V.Kurdyumov Institute for Metal Physics.

M.S. BRODYN, A.G. ZAGORODNY, A.G. NAUMOVETS, V.M. LOKTEV, S.V. PELETMINSKII, B.O. IVANOV, YU.I. GOROBETS, I.V. LEZHNENKO 